\title{
Intravesical gemcitabine versus mitomycin for non-muscle invasive bladder cancer: a systematic review and meta-analysis of randomized controlled trial
}

Rongxin $\mathrm{Li}^{1 \dagger}$, Ye $\mathrm{Li}^{1 \dagger}$, Jun Song ${ }^{1,2 \dagger}$, Ke Gao ${ }^{1}$, Kangning Chen ${ }^{1}$, Xiaogang Yang ${ }^{1}$, Yongqiang Ding ${ }^{1}$, Xinlong Ma ${ }^{1}$, Yang Wang ${ }^{1}$, Weipeng $\mathrm{Li}^{1}$, Yanan Wang ${ }^{1}$, Zhiping Wang ${ }^{1}$ and Zhilong Dong ${ }^{1 *}$

\begin{abstract}
Background: Mitomycin (MMC) has been frequently used as the compound for intravesical treatment. The relatively new pyrimidine analog gemcitabine (GEM) has exhibited anticancer effect on various solid cancers, such as the advanced bladder cancer. In this study, the GEM and MMC in treating non-muscle invasive bladder cancer (NMIBC) cases was compared through systemic review.

Methods: In accordance with the Preferred Reporting Items for Systematic Reviews and Meta-Analyses (PRISMA) statement, the electronic databases, including Embase, PubMed, Chinese biomedicine literature database, the Cochrane Library, the National Institute for Health and Clinical Excellence, NHS Evidence, Chinese technological periodical full-text database, and Chinese periodical full-text database, were systemically reviewed from inception to October 2018. Then, the RevMan 5.0 software was applied for data analysis. Five randomized controlled trials (RCTs) involving a total of 335 patients were included.

Results: For MMC group, the recurrence rate in the mitomycin arm increased compared with that in GEM group $(\mathrm{OR}=0.4495 \% \mathrm{Cl}[0.24,0.78])$, and the difference was statistically significant between the two groups. GEM was associated with reduced incidence of chemical cystitis compared with that of $\mathrm{MMC}(\mathrm{OR}=0.2395 \% \mathrm{Cl}[0.12,0.44])$. Differences in hematuria $(\mathrm{OR}=0.4695 \% \mathrm{Cl}[0.16,1.31])$, skin reaction $(\mathrm{OR}=0.4995 \% \mathrm{Cl}[0.14,1.70])$ and liver and kidney function damage $(\mathrm{OR}=0.5195 \% \mathrm{Cl}[0.09,2.85])$ displayed no statistical significance between the two groups.

Conclusion: Findings in our study demonstrate the superior efficacy of GEM over MMC in reducing the relapse rate among NMIBC patients following transurethral resection (TUR). In addition, GEM is associated with reduced local toxic effects on the bladder compared with those of MMC. However, more future studies are needed to examine GEM safety when used as the monotherapy or polytherapy for bladder patients. More RCTs with high quality are also required to validate our findings due to the limitations of the current meta-analysis.
\end{abstract}

Keywords: Bladder cancer, Gemcitabine, Mitomycin, Systematic evaluation, Meta-analysis

\footnotetext{
* Correspondence: 562691313@qq.com

${ }^{\dagger}$ Rongxin Li' Ye Li and Jun Song made equal contribution to this manuscript and should be regarded as co-first authors.

'Lanzhou University Second Hospital, Lanzhou City, Gansu Province, China

Full list of author information is available at the end of the article
}

(c) The Author(s). 2020 Open Access This article is licensed under a Creative Commons Attribution 4.0 International License, which permits use, sharing, adaptation, distribution and reproduction in any medium or format, as long as you give appropriate credit to the original author(s) and the source, provide a link to the Creative Commons licence, and indicate if changes were made. The images or other third party material in this article are included in the article's Creative Commons licence, unless indicated otherwise in a credit line to the material. If material is not included in the article's Creative Commons licence and your intended use is not permitted by statutory regulation or exceeds the permitted use, you will need to obtain permission directly from the copyright holder. To view a copy of this licence, visit http://creativecommons.org/licenses/by/4.0/. The Creative Commons Public Domain Dedication waiver (http://creativecommons.org/publicdomain/zero/1.0/) applies to the data made available in this article, unless otherwise stated in a credit line to the data. 


\section{Background}

Bladder cancer has become a common cancer worldwide, and 430,000 new cases and over 165,000 deaths are reported in 2012 [1]. Transitional cell carcinoma is dominant in bladder cancer, in addition, adenocarcinoma (cancer originating from the mucus-making and releasing cells) and squamous cell carcinoma (cancer originating from the thin and flat cells) are also observed [2]. Generally, bladder cancer is associated with the following symptoms, frequent urination, bloody urine (rendering the slight rusty to deep red color of urine), urination pain, or urination sensation with no urine indeed [3].

The incidences of bladder cancer in male and female are reported to be 3.4 and $1.2 \%$, respectively, however, that in patients aged over 70 years is twice to thrice higher than that among patients aged 55-65 years, and 15 to 20 times greater than for patients aged $30-54$ years [4]. As estimated by the World Health Organization, there were 132,432 bladder cancer-related deaths in the world in 2000 [5].

About $80 \%$ bladder cancers are non-muscle invasive bladder cancers (NMIBC) restricted to the urothelium (clinical stage $\mathrm{Ta}$ ) or lamina propria (stage $\mathrm{T} 1$ ) at first, which is featured by the in-situ flat carcinoma (stage Tis) [6]. Tumor relapse following transurethral resection (TUR) has been identified as a main issue in treating non-muscle invasive bladder cancer. Specifically, the mechanisms regarding NMIBC relapse following TUR are shown as follows, (1) residual tumor originated from the incomplete resection; (2) floating cancer cell implantation in traumatized bladder sites; (3) incidence of new neoplasm due to high cancer aggressiveness; (4) relapses at the urothelial instability sites (atypia, hyperplasia and dysplasia) [7]; (5) over $50-70 \%$ tumor relapse since no adjuvant treatment is given, and approximately $15 \%$ cases develop muscle-invasive cancers eventually [8].

The intravesical chemotherapy has been considered as the standard treatment for patients receiving following TUR to eradicate underlying disorders, inhibit cancer relapse, prevent tumor development and extend patient survival [9]. Mitomycin (MMC) is a frequently used compound in intravesical treatment. In addition, gemcitabine (GEM), the relatively new pyrimidine analog, displays anticancer effect on various solid cancers, such as the advanced bladder cancer [10]. MMC and GEM have been classically used as the cytotoxic agents for affecting the DNA integrity, but these two display distinctly different mechanisms of action. Among them, GEM, the difluoro-2, 2-deoxy-cytidine, can be activated upon the stimulation of deoxycytidine kinase, meanwhile, its phosphorylated metabolites may impact the synthesis of deoxy-nucleotide through resulting in DNA injuries and interfering with DNA repair [11]. On the other hand, MMC can be triggered within cancer cells through forming the reducing equivalents, thereby affecting cancer cell replication through forming the damage-induced DNA adducts [12]. Nonetheless, it remains unclear about the efficacy and side effects between the two agents. In this regard, the current systematic review was carried out aiming to evaluate the therapeutic effects and safety between GEM versus MMC on treating NMIBC patients.

\section{Methods}

\section{Search strategy}

In accordance with Preferred Reporting Items for Systematic Reviews and Meta-Analyses (PRISMA) statement [13], the electronic databases, including Embase, PubMed, Chinese biomedicine literature database, the Cochrane Library, the National Institute for Health and Clinical Excellence, NHS Evidence, Chinese periodical full-text database, and Chinese technological periodical full-text database, were systemically reviewed from inception to October 2018 to identify the randomized controlled trials (RCTs) that compared the efficacy and safety of GEM and MMC in treating NMIBC cases. Additionally, the critical Chinese magazines in relevant fields were also retrieved manually, corresponding search engines were employed to identify the relevant references, and each reference in the enrolled articles was retrieved as well to discover other possible relevant publications. Related terms were used for study retrieval. Moreover, the reference lists from those enrolled articles and reviews were also manually retrieved, and experts in this field were contacted if necessary, while those nonpublished articles were not found. The study retrieval was not restricted by language.

In this study, the following search terms were used in retrieval strategy, including intravesical pharmacotherapy, non-muscle invasive bladder cancer, gemcitabine and mitomycin, so as to find out the titles and abstracts of relevant studies. To be specific, the entire retrieval strategy adopted in the current work for the PubMed database included (irrigation of bladder OR intravesical therapy OR bladder instillation OR intravesical instillation OR intravesical infusion OR infusion of bladder) AND (non-muscle-invasive bladder cancer OR NMIBC OR non-muscle invasive bladder cancer OR superficial bladder cancer) AND (GEM OR gemcitabine) AND (MMC OR mitomycin OR mitomycin-c).

\section{Data collection}

Two researchers independently reviewed those retrieved titles and abstracts in accordance with the study inclusion criteria, and the inappropriate articles were excluded. Any disagreement between them was settled 
down through the opinion from a third author. Afterwards, data were extracted by the same authors independently by the use of the uniform data collection forms. Besides, the evaluated quality items included the concealment of allocation, randomization, blinding (subjects, researchers, outcome measures, data analysis), as well as follow-up completeness [14].

\section{Inclusion and exclusion criteria}

The study inclusion criteria were shown as follows: (1) randomized controlled trials (RCTs) as well as quasiRCTs (namely, RCTs adopting the quasi-random method for participating allocation into various intervention groups); (2) studies that comprised medium- to high-risk patients (with high-grade papillary stage Ta or T1 tumors and any patient with carcinoma in situ) who occupies 15-44\% NMIBC cases in certain series [15]; (3) studies that mentioned clinical outcomes, $\mathrm{Ta}$ or $\mathrm{T} 1$ tumor and included patients receiving intravesical gemcitabine comparing with mitomycin.

The study exclusion criteria were as follows: (1) nonRCTs; (2) studies in which cases with other neoplasm; (3) studies with incomplete information to analysis; (4) duplicate articles.

\section{Outcome measure types}

Tumor relapse rate, and local side effects (including chemical cystitis, hematuria, skin reaction, and liver and kidney function damage).

\section{Intervention types}

Intravesical treatment with GEM or MMC following TUR.

\section{Statistical analysis}

All dichotomous outcomes (such as recurrence, mortality, progression of tumor staging, distant metastasis, systemic and local adverse reaction, treatment delay or withdrawal) were presented in the manner of relative risk (RR) and the corresponding 95\% confidence intervals $(\mathrm{CI})$. The data were extracted and pooled using the random-effects model. For guaranteeing our model robustness and outlier susceptibility, we also adopted the fixed-effect model for analysis. The statistical heterogeneities across different trials were tested using the chisquare heterogeneity test while the inconsistency degree was assessed by $\mathrm{I}^{2}$ statistic, with the threshold of $p=$ 0.10 , and $p<0.1$ indicated the presence of statistical heterogeneity across various studies. Thereafter, subgroup analyses, sensitivity analysis, and the random effects model were carried out in the presence of heterogeneity. The potential heterogeneity sources were explored through subgroup analysis. The putative factor impacts on the effect size were explored through sensitivity analysis. The descriptive approaches were adopted for tabulating and assessing the adverse effects, as they were possibly distinct for our examined agents.

\section{Results}

\section{Search results}

Figure 1 displays the study retrieval and screening procedure. A total of 213 preliminary studies were retrieved initially, among which, 208 were ruled out from this study later. Finally, 5 RCTs including 335 cases were included [16-20], all of which mentioned outcomes including recurrence rate and toxicity evaluation (chemical cystitis, hematuria, skin reaction, and liver and kidney function damage).

\section{Included study features and quality}

Table 1 displays the enrolled study features and quality. Table 2 presents the patient features and drug administration schedule.

\section{Meta-analysis results \\ Treatment efficacy}

For MMC group, the recurrence rate increased compared with that of GEM group (OR $=0.4495 \% \mathrm{CI}[0.24$, $0.78]$ ), and the difference was of statistical significance between the two groups, as shown in Figs. 2 and 3.

\section{Adverse effects}

Five trials reported the local adverse effects. The most commonly reported adverse effects in both groups were chemical cystitis $(\mathrm{OR}=0.23 \quad 95 \%$ CI $[0.12,0.44])$, hematuria $(\mathrm{OR}=0.4695 \% \mathrm{CI}[0.16,1.31])$, skin reaction $(\mathrm{OR}=0.4995 \% \mathrm{CI}[0.14,1.70])$ and liver and kidney function damage $(\mathrm{OR}=0.5195 \%$ CI $[0.09,2.85])$. According to our results, GEM was associated with reduced local toxicity relative to mitomycin. Overall, these two doses were well tolerable among a majority of cases with reduced adverse reactions.

\section{Discussion}

Meta-analysis is an approach adopted to statistically pooled and examined the findings from several independent RCTs [21]. NMIBC is generally associated with favorable clinical outcomes, but it is refractory due to the increased tumor relapse rate following TUR. As a matter of fact, $40-85 \%$ cases develop tumor relapse in 2-5 years following standardized TUR, while approximately $10 \%$ among such relapse patients are at the more advanced grade and stage [22]. In clinical practice, TUR is performed prior to intravesical injection with chemotherapeutic or the agents for modulating immunity, so as to lower the bladder cancer relapse and development.

Various anti-cancer agents are administered intravesically to prevent tumor relapse, which is validated as 


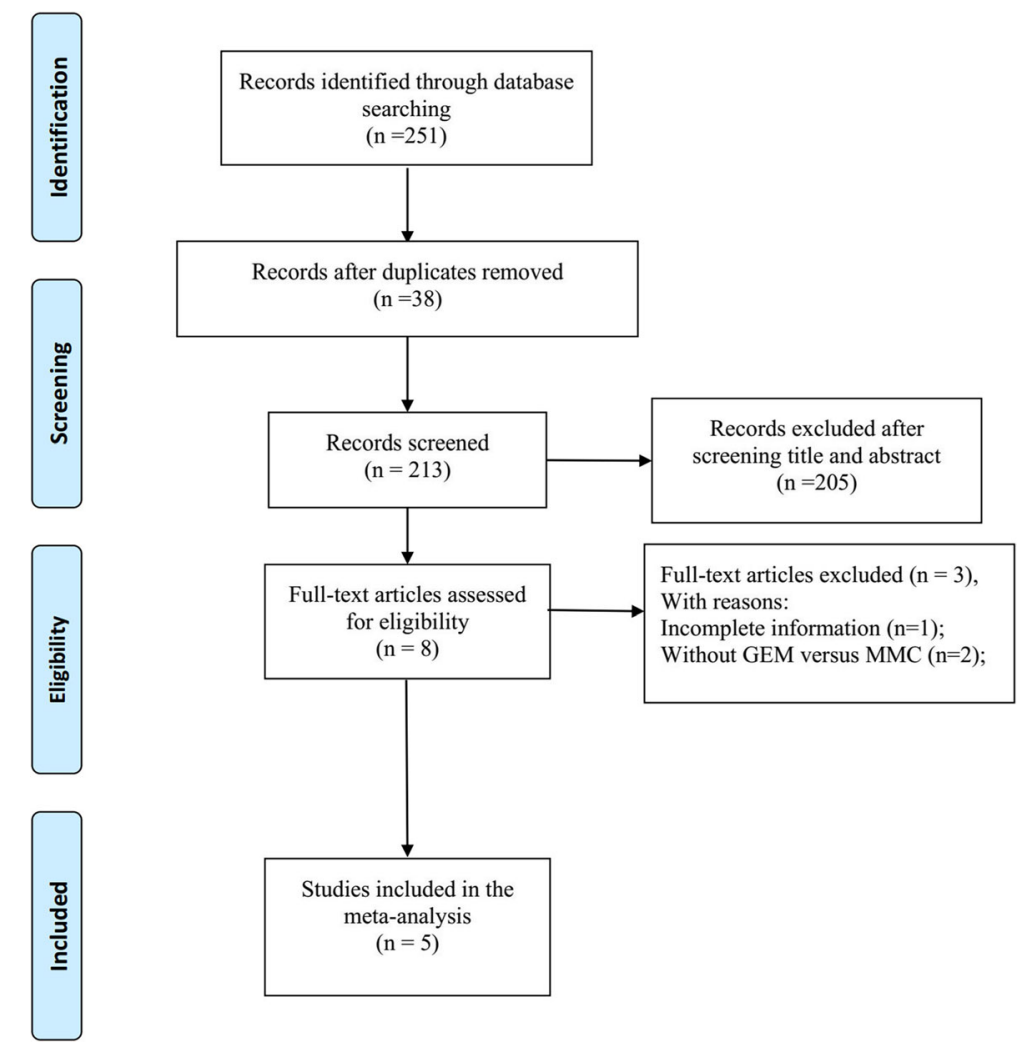

Fig. 1 PRISMA flow diagram: the study selection process

effective. The classical intravesical agents, Bacille Calmette-Guérin (BCG) as well as MMC are effective on postponing and lowering the postoperative tumor relapse rate; nonetheless, they are also associated with obvious adverse reactions and may be ineffective for some cases. Based on clinical research, GEM is effective on reducing the relapse of non-muscle invasive bladder cancer with lower toxicity, which deserves more investigation [23]. In this study, the meta-analysis was carried out to examine the intravesical GEM and MMC safety and efficacy among the NMIBC patients on the basis of the five enrolled clinical trials including 335 bladder cancer cases. Three of those 5 articles mentioned disease grade and stage $[17,19,20]$. Our results showed that the recurrence rate of MMC group increased compared with that of GEM group $(\mathrm{OR}=0.44$
95\% CI $[0.24,0.78])$, and the difference was statistically significant between the two groups; besides, GEM led to a lower incidence of chemical cystitis than MMC $(\mathrm{OR}=$ $0.2395 \% \mathrm{CI}[0.12,0.44])$. But differences in the incidences of hematuria $(\mathrm{OR}=0.4695 \% \mathrm{CI}[0.16,1.31])$, skin reaction $(\mathrm{OR}=0.4995 \% \mathrm{CI}[0.14,1.70])$ and liver and kidney function damage $(\mathrm{OR}=0.5195 \%$ CI $[0.09$, 2.85]) were not statistically significant between the two groups., suggesting that GEM had lower toxicity than MMC. Overall, these two doses were well-tolerable among a majority of cases with lower adverse reactions. Nonetheless, the above conclusions must be interpreted carefully and validated in more articles.

For the low risk disorder, post-operative intravesical MMC treatment is still the vital part of intravesical therapy, meanwhile, there is level-one evidence to prove the

Table 1 The quality and characteristics of included studies

\begin{tabular}{lllllll}
\hline Study & Randomization & $\begin{array}{l}\text { Allocated } \\
\text { Concealment }\end{array}$ & Blinding & Gemcitabine (sample size) & Mitomycin (sample size) & Grade \\
\hline Dong 2017 [16] & adequate & not used & clear & 12 & 16 & C \\
Lin 2016 [17] & adequate & not used & clear & 42 & 42 & C \\
Sun 2016 [18] & adequate & used & clear & 30 & 28 & B \\
Xiaohong 2015 [19] & adequate & not used & clear & 27 & S & C \\
Raffaele 2010 [20] & adequate & used & clear & 54 & B \\
\hline
\end{tabular}




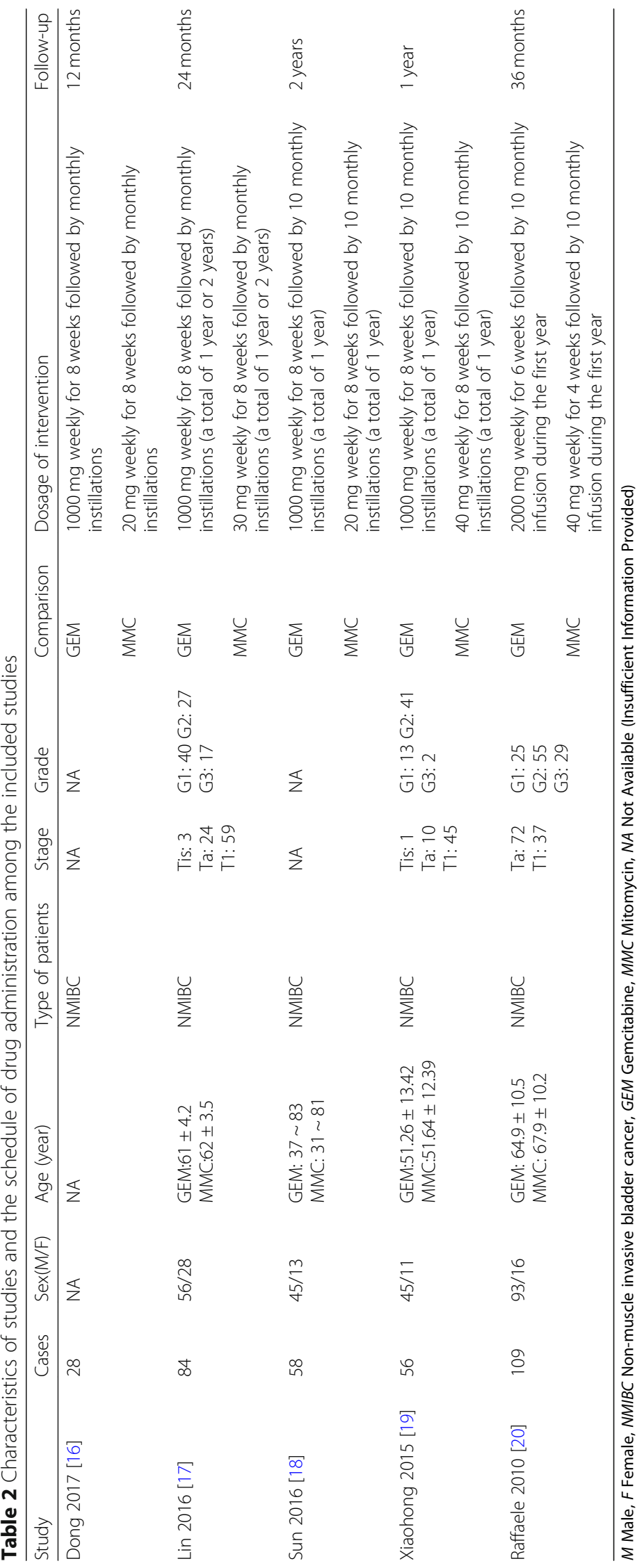




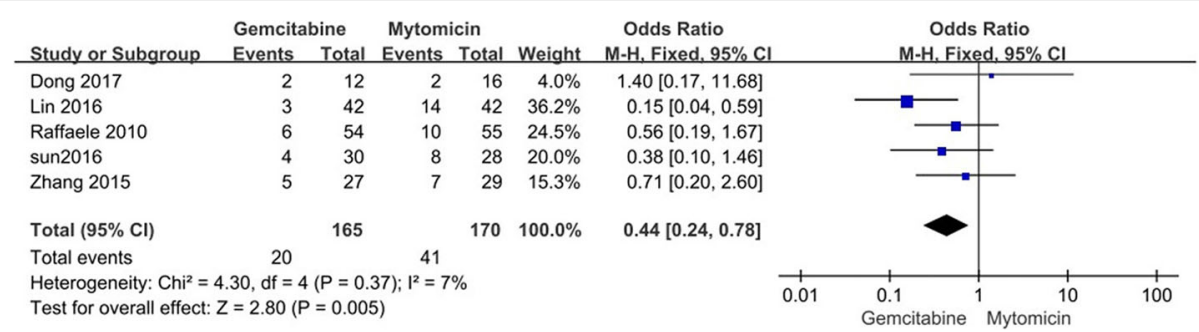

Fig. 2 Recurrence rates: gemcitabine versus mitomycin

effectiveness of GEM on bladder cancer, yet it has not been recommended in guidelines [24]. Many therapeutic methods are effective on the treatment of NMIBC cases. The intravesical chemotherapy using MMC and GEM has achieved certain favorable results [25]. Gemcitabine is an effective pyrimidine antimetabolite, with only mild toxicity relative to other chemotherapeutic agents [26]. According to Messing EM et al. [27], for the low-grade NMIBC cases $(n=215)$, those receiving intravesical GEM treatment following TUR were associated with the 4 -year tumor relapse rate of $34 \%$, while that in the saline-alone control group was $54 \%$. In addition, 5 cases of GEM group and 10 in control group progressed to muscle invasive bladder cancer, and 17 of GEM group as well as 25 of saline group died. Based on Dalbagni et al., for the 30 BCG-refractory NMIBC cases (including uncontrollable $\mathrm{Ta}$, multiple unresected $\mathrm{T} 1$, and refractory cancer in situ) who underwent intravesical GEM treatment regularly, $50 \%$ achieved a complete response (CR), and adverse effects were reported among $23 \%$ cases with a very low toxicity [28]. Moreover, according to Bartoletti et al., no 1-year tumor relapse was reported among 18 out of the 24 medium-risk patients, as well as among 9 out of the 16 high-risk BCG-refractory cases (pTa pT1) treated with weekly intravesical GEM therapy. In that study, no side effect was reported in 94 of the 116 patients in the 1-year treatment process [29]. Jones et al. reviewed 6 GEM treatment-related RCTs in their

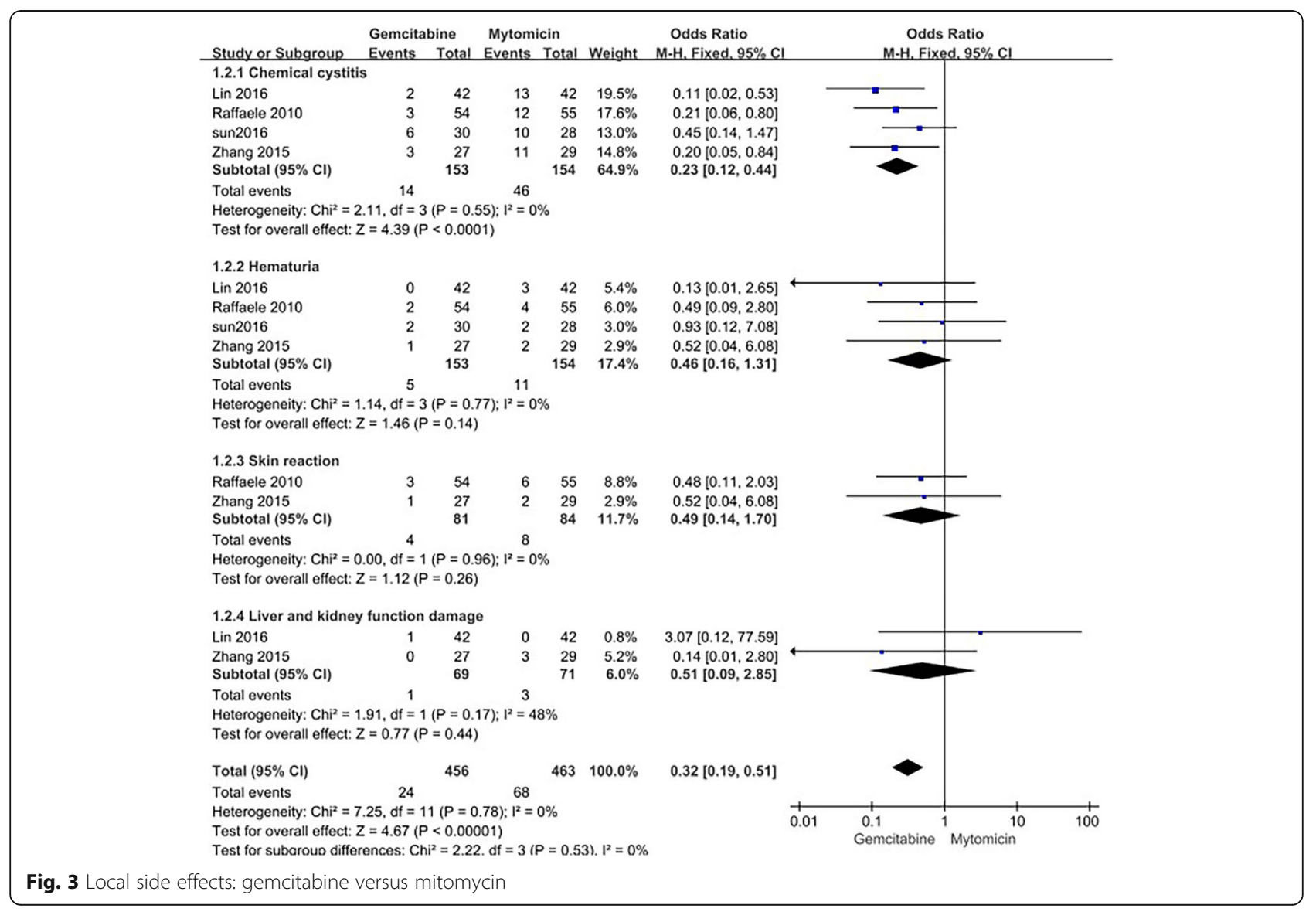


Cochrane review, and indicated that, intravesical GEM treatment potentially exerted an important part in managing NMIBC cases with moderate and high risk, particularly when it was adopted to be the alternative to MMC for high-risk cases [30].

Auxiliary intravesical treatment can lower the relapse and development rates of NMIBC in the meantime of inducing local and systemic adverse reactions. In terms of the toxic effects, chemical cystitis, hematuria, skin reaction, and liver and kidney function damage were observed in $0-30 \%$ cases of each group. The frequency of these side effects of GEM arm markedly decreased compared with that of MMC arm. Such findings validated that, chemical cystitis, the irritable symptom in lower urinary tract, stands for the typical MMC side reaction [31]. GEM led to minimal local toxicity, which was selfresolved rapidly. By contrast, MMC treatment resulted in the more serious local toxicity that required treatment delay. On the other hand, economic influence is also a factor potentially affecting the treatment decisionmaking. Recently, the mean sales price for $40 \mathrm{mg}$ MMC markedly increases compared with that for $2 \mathrm{~g}$ GEM, suggesting that the GEM-based intravesical chemotherapy is advantageous over MMC in price [32].

Some limitations should be noted in the current metaanalysis: 1) the risk of tumor relapse was not compared between GEM and MMC of Ta or T1 group due to the limited total sample size, so more high-quality RCTs should be carried out. 2) The administration does and schedules of these two agents were similar among those five enrolled studies, but the conclusion might be disturbed by the clinical heterogeneity because of the differences in operating methods, like whether the positional changes were allowed, as well as the duration of each infusion. 3) All included RCTs in the current review did not apply the double-blinding method, which might potentially impact our results. 4) The publication bias was not totally ruled out, which possibly led to conclusion distortion.

\section{Conclusions}

In conclusion, our meta-analysis supports that GEM can be a potential agent of intravesical therapy with better efficiency than MMC in preventing recurrence of patients with non-muscle invasive bladder cancer after TUR. At the same time, we observed that GEM produce lower local toxic effects than MMC during intravesical therapy. In addition, more studies are needed to examine the GEM safety, and more high-quality RCTs are warranted to validate our conclusions due to the limitations.

\section{Abbreviations}

BCG: Bacille Calmette-Guérin; Cl: Confidence intervals; GEM: Gemcitabine MMC: Mitomycin C; NMIBC: Non-muscle-invasive bladder cancers;
PRISMA: Preferred Reporting Items for Systematic Reviews and MetaAnalyses; RCTs: Randomized controlled trials; TUR: Transurethral resection

\section{Acknowledgments}

None

\section{Authors' contributions}

WZP, DZL, LRX and SJ were responsible for study conception and design. $L R X, L Y$, and $S J$ were in charge of manuscript writing and editing. $L R X, G K$, CKN, DYQ, YXG, MXY, and WY contributed to data collection. LRX, GK, CKN, $D Y Q, Y X G, M X Y, W Y, L W P$, and WYN were responsible for data management/ analysis. Each of the author had carefully read and approved the final manuscript for publication.

\section{Funding}

This work was supported by The Second Hospital of Lanzhou University Project. The funding body was not involved in study design, data extraction, analysis, and description, or manuscript writing.

Availability of data and materials

The datasets used and/or analyzed during the current study are available from the corresponding author on reasonable request.

Ethics approval and consent to participate

Not applicable.

\section{Consent for publication}

Not applicable.

\section{Competing interests}

The authors declare that they have no conflict of interest.

\section{Author details}

${ }^{1}$ Lanzhou University Second Hospital, Lanzhou City, Gansu Province, China. ${ }^{2}$ Sanya People's Hospital, Sanya City, Hainan Province, China.

Received: 11 August 2019 Accepted: 6 April 2020

Published online: 13 July 2020

\section{References}

1. Antoni S, Ferlay J, Soerjomataram I, et al. Bladder Cancer incidence and mortality: a global overview and recent trends. Eur Urol. 2017;71:96-108.

2. Tanaka T, Miyazawa K, Tsukamoto T, Kuno T, Suzuki K. Pathobiology and chemoprevention of bladder Cancer. J Oncol. 2011;2011:528-53.

3. Cabello MJ, Grau L, Franco N, Orenes E, Alvarez M, Blanca A, Heredero O, Palacios A, Urrutia M, Fernández JM, López-Beltrán A, Sánchez-Carbayo M. Multiplexed methylation profiles of tumor suppressor genes in bladder Cancer. J MolDiagn. 2011;13:29-40.

4. Pasbos CL. Bladder cancer, epidemiology, diagnosis, and management. Cancer Pract. 2002;10:311-22.

5. Ferlay J, Bray F, Pisani P, Parkin DM. GLOBOCAN 2000: Cancer incidence, mortality and prevalence worldwide. IARC CancerBase no. 5. Lyon: IARC Press; 2001.

6. Uekado Y, Hirano A, Shinka T, Ohkawa T. The effects of intravesical chemoimmunotherapy with epirubicin and bacillus Calmette-Guerin for prophylaxis of recurrence of superficial bladder cancer: a preliminary report. Cancer Chemother Pharmacol. 1994;35:65-8.

7. Ray ER, O'Brien TS. Approaches to reducing recurrence in superficial bladder cancer. Eur Kidney Urol Dis. 2006;1:1-6.

8. Herr HW, Laudone VP, Whitmore WF Jr. An overview of intravesical therapy for superficial bladder tumors. J Urol. 1987;138:1363-8.

9. Whelan P. The treatment of non-muscle-invasive bladder Cancer with Intravesical chemotherapy and immunotherapy. Eur Urol Suppl. 2007;6:568-71.

10. Stadler WM, Kuzel T, Roth B, et al. Phase II study of single-agent gemcitabine in previously untreated patients with metastatic urothelial cancer. J Clin Oncol. 1997;15:3394-8.

11. Plunkett W, Huang P, Searcy CE, et al. Gemcitabine: preclinical pharmacology and mechanisms of action. Semin Oncol. 1996;23:3-15.

12. Joudi FN, O'Donnel MA. Second-line intravesical therapy versus cystectomy for Bacile Calmette-Gue'rin (BCG) failure. Curr Opin Urol. 2004;14:271-5. 
13. Liberati A, Altman DG, Tetzlaff J, et al. The PRISMA statement for reporting systematic reviews and meta-analyses of studies that evaluate health care interventions: explanation and elaboration. J Clin Epidemiol. 2009;62(10):e1e34.

14. Dong ZL, Yang KH, Liu YL, Mi DH, Wang ZP, Tian JH. Intravesical doxorubicin versus epirubicin for superficial bladder cancer. Cochrane Database Syst Rev. 2010, Issue 1. Art. No.CD008181. https://doi.org/10.1002/ 14651858.CD008181.

15. Oosterlinck. Guidelines on bladder cancer. Eur Urol. 2002;41:105-12

16. Dong X, Song L, Zhang F. Curative effect analysis of different chemotherapeutics at intravesical instillation in the prevention of tumor recurrence after TUR-Bt. Zhejiang J Traumat Surg. 2017;22:109-10.

17. Lin T, Sun L. Comparison of the efficacy of different chemotherapy drugs in the prevention of postoperative recurrence in superficial bladder cancer by intravesical instillation. China Foreign Med Treat. 2016;35:118-9.

18. Sun $\mathrm{S}$, Liu R, Zhao H, et al. Comparison of intravesical perfusion of gemcitabine and mitomycin after non-muscle invasive bladder cancer. J Med Theory Pract. 2016;29:3238-9.

19. Xiaohong Z, Tan J, Wei Y, et al. Clinical effect of antineoplastic drug perfusion in preventing postoperative recurrence of superficial bladder cancer. J Chin Physician. 2015;17:1043-5.

20. Addeo R, Caraglia M, Bellini S, et al. Randomized phase III trial on gemcitabine versus Mitomycin in recurrent superficial bladder Cancer: evaluation of efficacy and tolerance. J Clin Oncol. 2010;28:543-8.

21. Lau J, loannidis JP, Schmid CH. Summing up evidence: oneanswer is not always enough. Lancet. 1998:351:123-7.

22. Shariat SF, Chade DC, Karakiewicz Pl, Scherr DS, Dalbagni G. Update on intravesical agents for non-muscle-invasive bladder cancer. Immunotherapy, vol. 2; 2010. p. 381-92.

23. Shelley MD, Jones $\mathrm{G}$, Cleves $\mathrm{A}$, et al. Intravesical gemcitabine therapy for non-muscle invasive bladder cancer (NMIBC): a systematic review. BJU Int. 2012;109:496-505.

24. Peyton CC, Chipollini J, Azizi M, et al. Updates on the use of intravesical therapies for non-muscle invasive bladder cancer: how, when and what. World J Urol. 2018. https://doi.org/10.1007/s00345-018-2591-1.

25. Stein JP, Lieskovsky G, Cole R, et al. Radical cystectomy in the treatment of invasive bladder cancer: long term results in 1054 patients. J Clin Oncol. 2001;19:666-75.

26. Schlack K, Boegemann M, Steinestel J, Schrader AJ, Krabbe LM. The safety and efficacy of gemcitabine for the treatment of bladder cancer. Expert Rev Anticancer Ther. 2016;16:255-71.

27. Messing EM, Tangen CM, Lerner SP, et al. Effect of Intravesical instillation of gemcitabine vs saline immediately following resection of suspected lowgrade non-muscle-invasive bladder Cancer on tumor recurrence: SWOG S0337 randomized clinical trial. JAMA. 2018;319(18):1880-8.

28. Dalbagni G, Russo P, Bochner B, et al. Phase II trial of intravesica gemcitabine in bacille Calmette Guerin-refractory transitional cell carcinoma of the bladder. J Clin Oncol. 2006;24:2729-34.

29. Bartoletti R, Cai T, Gacci M, et al. Intravesical gemcitabine therapy for superficial transitional cell carcinoma: results of a phase II prospective multicenter study. Urology. 2005;66:726-31.

30. Bolenz C, Cao Y, Arancibia MF, et al. Intravesical mitomycin C for superficial transitional cell carcinoma. Expert Anticancer Ther. 2006;6:1273-82.

31. Jones G, Cleves A, Wilt TJ, Mason M, Kynaston HG, Shelley M. Intravesical gemcitabine for non-muscle invasive bladder cancer. Cochrane Database Syst Rev. 2012;1:CD009294 Published 2012 Jan 18.

32. Centers for Medicare \& Medicaid Services. 2020 ASP Drug Pricing Files https://www.cms.gov/medicare/medicare-part-b-drug-average-sales-price/2 020-asp-drug-pricing-files. Accessed 5 Jan 2020.

\section{Publisher's Note}

Springer Nature remains neutral with regard to jurisdictional claims in published maps and institutional affiliations.

Ready to submit your research? Choose BMC and benefit from:

- fast, convenient online submission

- thorough peer review by experienced researchers in your field

- rapid publication on acceptance

- support for research data, including large and complex data types

- gold Open Access which fosters wider collaboration and increased citations

- maximum visibility for your research: over $100 \mathrm{M}$ website views per year

At $\mathrm{BMC}$, research is always in progress.

Learn more biomedcentral.com/submissions 